\title{
The association of the N-terminal pro-brain- type natriuretic peptide response to exercise with disease severity in therapy- naive pulmonary arterial hypertension: a cohort study
}

\author{
J. Kutsch, C. Faul, W. von Scheidt, M. Schwaiblmair and T. M. Berghaus*
}

\begin{abstract}
Background: While the N-terminal pro-brain-type natriuretic peptide (NT-proBNP) at rest is known to be associated with prognosis in pulmonary arterial hypertension $(\mathrm{PAH})$, it is unclear if the NT-proBNP response to exercise ( $\triangle N T$-proBNP) can contribute to a better assessment of disease severity.

Methods: We investigated the association of NT-proBNP values at rest and during peak exercise with hemodynamics and cardiopulmonary exercise testing parameters in 63 therapy-naive PAH patients.

Results: The median NT-proBNP increases from 1414 at rest to $1500 \mathrm{pg} / \mathrm{ml}$ at peak exercise. The $\Delta N T$-proBNP is baselinedependent in PAH. Both, NT-proBNP at rest and NT-proBNP at peak exercise, are significantly correlated with hemodynamics and functional capacity. However, neither NT-proBNP at peak exercise nor $\Delta$ NT-proBNP correlated better with surrogate markers of disease severity than NT-proBNP at rest.
\end{abstract}

Conclusion: The $\triangle N T$-proBNP does not contribute to a better assessment of disease severity in PAH.

Keywords: N-terminal pro-brain-type natriuretic peptide (NT-proBNP), Response to exercise, Pulmonary arterial hypertension (PAH), Exercise capacity, Hemodynamics

\section{Background}

Although medical therapy is available, pulmonary arterial hypertension (PAH) is a progressive disease leading to a reduction in exercise capacity and, more severely, to a decreased life expectancy [1]. In order to evaluate the progress of the disease, a number of prognostic parameters were established, including hemodynamics and cardiopulmonary exercise testing (CPET) [2].

As right ventricular (RV) dysfunction is one of the most important factors contributing to functional impairment and mortality [3], the plasma concentration of N-terminal pro-brain-type natriuretic peptide (NTproBNP) is supposed to be another prognostic marker.

\footnotetext{
*Correspondence: thomas.berghaus@klinikum-augsburg.de Department of Cardiology, Respiratory Medicine and Intensive Care, Klinikum Augsburg, Ludwig-Maximilians-University Munich, Stenglinstrasse 2, 86156 Augsburg, Germany
}

NT-proBNP is formed through enzymatic cleavage of proBNP into the two split products NT-proBNP and the biologically active BNP. ProBNP is released from the myocytes mainly in response to cardiac wall stress. BNP and NT-proBNP are produced on an equimolar basis, however, as NT-proBNP has a longer half-life and higher sample stability, NT-proBNP is the more advantageous gnostic marker [4]. proBNP response to exercise ( $\triangle \mathrm{NT}$-proBNP) can contribute to a better assessment of disease severity. Therefore, we investigated the association of NT-proBNP values at rest and during peak exercise with hemodynamics and functional capacity, important surrogate parameters of disease severity in PAH. 


\section{Methods}

\section{Study design}

From August 2009 until March 2016, 63 therapy-naive PAH patients were recruited. Patients with a serum creatinine of $>1.3 \mathrm{mg} / \mathrm{dl}$, a glomerular filtration rate $<$ $50 \mathrm{ml} / \mathrm{min} / 1.73 \mathrm{~m}^{2}$, congenital heart diseases or signs of acute right heart decompensation were excluded from the study. All study participants underwent six-minute walking testing (6MWT), CPET, lung function testing and right heart catheterisation. Evaluation of exercise capacity and hemodynamics were used as surrogate parameters of disease severity in our trial. All examinations were performed within three consecutive workdays. The study was approved by the local Ethics Committee (project number 201604). Data analysis was performed retrospectively.

\section{Right heart catheterisation}

In order to confirm precapillary pulmonary hypertension $(\mathrm{PH})$, all patients underwent right heart catheterisation. A thermodilution catheter $(7.5 \mathrm{~F}$ quadruple-lumen, balloon-tipped, flow-directed, „S "Tip Swan-Ganz Catheter, Edwards Lifesciences, Irvine, USA) was used. The catheter was inserted via the right or left femoral vein and hemodynamic measurements were taken in supine position. Those included heart rate, PCWP, PAP, cardiac output (CO), cardiac index (CI), pulmonary vascular resistance (PVR), right atrial pressure (RAP) and mixed venous oxygen saturation (SVO2). The $\mathrm{CO}$ was determined via thermodilution measurements. A computer system (Com-2, Cardiac Output Computer, Edwards Lifesciences, Irvine, USA) was used for calculations. $10 \mathrm{ml}$ sterile, ice-cold isotonic (0.9\%) saline was injected through the right atrial lumen of the catheter and measured by a thermistor placed directly behind the right atrial inlet of the catheter. The distal thermistor then recorded the drop in temperature. A minimum of three measurements was performed and the mean value was calculated provided that the variation was less than $10 \%$. The $\mathrm{CI}$ was calculated forming the quotient of $\mathrm{CO}$ and body surface area. PVR was computed using the standard formula [PVR $=($ mean PAP-PCWP $) / C O]$.

\section{Lung function test}

In order to examine the pulmonary function of the patients, spirometry and body plethysmography were performed. The diffusing capacity was tested via the single-breath method (Master Screen Body and MS-PFT, Jaeger, Cardinal Health, USA). Blood gas analysis was measured using arterialised capillary blood taken from the earlobe. No supplemental oxygen was given. Lung function parameters determined were total lung capacity
(TLC), forced vital capacity (FVC), forced expiratory volume in one second (FEV1) and diffusing capacity for carbon monoxide (DLCO).

\section{Cardiopulmonary exercise testing (CPET)}

An electromagnetically braked cycle ergometer (ViaSpring 150p, Ergoline, Germany) was used following a standardised protocol [6].

After a warming phase, the work rate elevated by 5 to 15 watts/min until the maximum exercise capacity was reached. This was defined as the moment when patients could no longer tolerate the symptoms. Maximum work rate was documented. While the pulse was continuously recorded, the blood pressure was measured noninvasively every two minutes. With an adult facemask (Vmax spectra 229 D, Sensor Medics, USA) minute ventilation (Ve) and $\mathrm{CO}_{2}$ output were recorded. The maximum $\mathrm{O}_{2}$ uptake (peak $\mathrm{VO} 2$ ) was determined taking the average $\mathrm{O}_{2}$ uptake during the last $15 \mathrm{~s}$ of CPET. Blood gas analysis was done at rest and at peak exercise. We calculated $\mathrm{O}_{2}$ pulse, alveolar-arterial $\mathrm{O}_{2}$ difference $(\mathrm{AaDO} 2)$ and functional dead space ventilation $(\mathrm{Vd} / \mathrm{Vt})$. The anaerobic threshold (AT) was defined as the $\mathrm{O}_{2}$ uptake patients reached in the moment the ventilatory equivalent for $\mathrm{O}_{2}(\mathrm{VE} / \mathrm{VO} 2)$ still increased and the ventilatory equivalent for $\mathrm{CO}_{2}\left(\mathrm{Ve} / \mathrm{CO}_{2}\right)$ decreased or stagnated. The VE/VCO2 slope was taken from the beginning of exercise until the respiratory compensation point, when acidaemia stimulated the ventilation and the end-tidal $\mathrm{CO}_{2}$ started to decrease.

\section{NT-proBNP}

NT-proBNP values were measured twice using capillary blood taken from the earlobe immediately before performing the CPET and after reaching peak exercise capacity. The one-step sandwich chemiluminescent immunoassay (Dimension Vista System, Siemens Healthcare Diagnostics Inc., Newark, USA) was used. In order to avoid an underestimation or overestimation of absolute values, measured NT-proBNP levels were divided by the age-adjusted normal upper range to calculate the normalised NT-proBNP ratio. Consequently, elevated levels result in a normalized NTproBNP ratio $>1$.

\section{Six-minute walking test (6MWT)}

Patients were encouraged to walk a $30 \mathrm{~m}$ long corridor as many times as possible in six minutes. The number of breaks was recorded. The achieved walking distance was set in ratio to age and gender. Immediately after the test, patients were asked to rate their perceived level of exhaustion on the Borg scale ranging from 0 (no dyspnea) to 10 (extreme dyspnea) [7]. 


\section{Statistics}

Statistical analysis was performed with IBM SPSS Statistics 23. Data was checked for normal distribution using graphic methods as well as the Shapiro-Wilk test. Mean and standard error of the mean (SEM) were calculated for data with normal distribution, median with range for those without.

Nominal variables are shown as numbers with percentage of total. We used the Spearman's rank correlation coefficient to examine the relation between NT-proBNP values and other parameters. Correlation is strongest if the coefficient is close to -1 or 1 . No correlation is apparent if the coefficient is 0 . Significance was tested two-tailed and assumed statistically significant if $p$-values were $<0.05$.

\section{Results}

Patients' characteristics

Sixty-three patients (32 females and 31 males, mean age $66.1 \pm 1.7$ years) could be included in our study. All study participants suffered from $\mathrm{PAH}$ with a mean PAP of $39.0 \pm 1.5 \mathrm{mmHg}$. The median NT-proBNP value at rest was $1414(38-13,538) \mathrm{pg} / \mathrm{ml}$. In Table 1 , further clinical characteristics of the study cohort are summarised.

\section{NT-proBNP levels in different risk groups}

Based on the NT-proBNP level at rest, the study population was divided into three groups. The NTproBNP $<300 \mathrm{pg} / \mathrm{ml}$ group showed a median response to exercise of $6 \mathrm{pg} / \mathrm{ml}$, the NT-proBNP 300$1400 \mathrm{pg} / \mathrm{ml}$ and the NT-proBNP $>1400 \mathrm{pg} / \mathrm{ml}$ groups showed higher absolute $\triangle \mathrm{NT}$-proBNP, $60 \mathrm{pg} / \mathrm{ml}$ and $200 \mathrm{pg} / \mathrm{ml}$, respectively. Additional information is shown in Table 2.

\section{Correlations of NT-proBNP and $\triangle$ NT-proBNP with hemodynamics and exercise capacity}

Strong and highly significant correlations were found between NT-proBNP at rest and at peak exercise with parameters of 6MWT, hemodynamics and CPET. With the majority of parameters, NT-proBNP at rest showed marginally better correlations than NT-proBNP at exercise. Exceptions are CO and PVR. In contrast, lung function parameters showed only weak correlations with NT-proBNP levels at rest or at peak exercise. The $\Delta$ NTproBNP only correlated significantly with the 6MWT distance, $\mathrm{AaDO}_{2}$ and the $\mathrm{Ve} / \mathrm{VCO}_{2}$ slope (see Table 3). Correlations of NT-proBNP and $\triangle \mathrm{NT}$-proBNP with the $6 \mathrm{MWT}$ distance, mean PAP and the $\mathrm{VO}_{2} / \mathrm{kg}$ are shown as plots in Additional file 1. They show that the correlations of $\triangle \mathrm{NT}$-proBNP values with hemodynamics and functional capacity are worse compared to NT-proBNP levels at rest or at peak exercise.
Table 1 Patients characteristics $(n=63)$

\begin{tabular}{|c|c|}
\hline \multicolumn{2}{|l|}{ Clinical profile } \\
\hline Female/male [n (\%)] & $32(50.2) / 31(49.8)$ \\
\hline Age (years) & $66.1 \pm 1.7$ \\
\hline $\mathrm{BMI}\left(\mathrm{kg} / \mathrm{m}^{2}\right)$ & $26.0(18.0-43.0)$ \\
\hline \multicolumn{2}{|l|}{ NT-proBNP } \\
\hline NT-proBNP at rest (pg/ml) & $1414(38-13,538)$ \\
\hline NT-proBNP at exercise $(\mathrm{pg} / \mathrm{ml})$ & $1500(42-14,365)$ \\
\hline NT-proBNP ratio & $6.95(0.09-60.60)$ \\
\hline$\Delta \mathrm{NT}$-proBNP $(\mathrm{pg} / \mathrm{ml})$ & $77(0-1160)$ \\
\hline \multicolumn{2}{|l|}{ 6-min walking test } \\
\hline Distance (m) & $300(100-570)$ \\
\hline$\%$ of norm $(\%)$ & $63.0 \pm 3.2$ \\
\hline Breaks (n) & $0(0-4)$ \\
\hline Borg scale points $(1-10)$ & $4(0-10)$ \\
\hline \multicolumn{2}{|l|}{ Right heart catheterisation } \\
\hline Mean PAP (mmHg) & $39.0 \pm 1.5$ \\
\hline Cardiac output (I/min) & $4.10(2.30-8.90)$ \\
\hline Cardiac index $\left(1 / \mathrm{min} / \mathrm{m}^{2}\right)$ & $2.35 \pm 0.10$ \\
\hline PVR (Wood Units) & $7.45(3.04-14.20)$ \\
\hline Mean RAP (mmHg) & $6.00(1.00-20.00)$ \\
\hline $\mathrm{SvO}_{2}(\%)$ & $61.1 \pm 1.04$ \\
\hline \multicolumn{2}{|l|}{ Lung function } \\
\hline DLCO (\%) & $52.6 \pm 3.30$ \\
\hline $\mathrm{PaO}_{2}$ at rest $(\mathrm{mmHg})$ & $58.0 \pm 1.70$ \\
\hline $\mathrm{PaO}_{2}$ at peak exercise $(\mathrm{mmHg})$ & $58.0 \pm 2.27$ \\
\hline \multicolumn{2}{|l|}{ Cardiopulmonary exercise testing } \\
\hline Work capacity (watts) & $45.0(25-122)$ \\
\hline $\mathrm{VO}_{2}(\mathrm{ml} / \mathrm{min})$ & $941 \pm 41.5$ \\
\hline $\mathrm{VO}_{2}(\mathrm{ml} / \mathrm{min} / \mathrm{kg})$ & $12.7 \pm 0.5$ \\
\hline AT $(\mathrm{ml} / \mathrm{min} / \mathrm{kg})$ & $9.43 \pm 0.37$ \\
\hline $\mathrm{O}_{2}$ pulse at peak exercise $(\mathrm{ml} / \mathrm{min} /$ beat $)$ & $8.46 \pm 0.34$ \\
\hline Ve (L/min) & $50.8 \pm 2.23$ \\
\hline $\mathrm{Ve} / \mathrm{NO}_{2}$ & $39.0(25.0-77.0)$ \\
\hline $\mathrm{Ve} / \mathrm{CO}_{2}$ & $44.0(28.0-87.0)$ \\
\hline $\mathrm{AaDO}_{2}(\mathrm{mmHg})$ & $48.1 \pm 2.2$ \\
\hline $\mathrm{Vd} / \mathrm{Nt}(\%)$ & $36.7 \pm 1.7$ \\
\hline Ve $\mathrm{NCO}_{2}$ Slope & $39.5(14.3-107)$ \\
\hline
\end{tabular}

When not stated otherwise, data are presented as mean \pm SEM or as median (range)

\section{Discussion}

Our study was conducted in order to evaluate if the NTproBNP response to exercise can contribute to a better assessment of disease severity in PAH.

First, we were able to demonstrate that NT-proBNP levels increase in response to exercise in PAH patients. Similar findings have already been made in studies 
Table 2 NT-proBNP response to exercise according to different NT-proBNP levels at rest

\begin{tabular}{|c|c|c|c|c|c|c|}
\hline NT-proBNP at rest & \multicolumn{2}{|c|}{$<300 \mathrm{pg} / \mathrm{ml}$} & \multicolumn{2}{|c|}{ 300-1400 pg/ml } & \multicolumn{2}{|c|}{$>1400 \mathrm{pg} / \mathrm{ml}$} \\
\hline Number (n) & 10 & & 21 & & 32 & \\
\hline NT-proBNP at rest & 84 & $(38-246)$ & 821 & $(426-1300)$ & 3145 & $(1414-13,538)$ \\
\hline NT-proBNP at exercise & 95 & $(42-281)$ & 844 & $(450-1500)$ & 3251 & $(1500-14,365)$ \\
\hline$\triangle N T$-proBNP absolute & 10 & $(0-49)$ & 60 & $(0-400)$ & 200 & $(0-1160)$ \\
\hline
\end{tabular}

When not stated otherwise, data are presented as median (minimum - maximum) in $\mathrm{pg} / \mathrm{ml}$

investigating left heart disease [8-10], and in one very small cohort, consisting of only 20 patients with precapillary $\mathrm{PH}$ [11]. However, there is another trial addressing the $\triangle$ NT-proBNP in PAH patients which showed no such effect [12]. While the design of the study was comparable to ours, patients investigated by Völkers and colleagues [12] were already on specific
PAH medication and showed much lower NT-proBNP levels at rest. In left heart disease, low NT-proBNP levels at rest are supposed to be strong predictors for low exercise-induced changes $[9,10]$. Thus, we divided our patients into three groups, based on the NT-proBNP levels at rest. The groups were formed according to the current NT-proBNP-based risk stratification model for

Table 3 Correlation of NT-proBNP and $\triangle$ NT-proBNP with hemodynamics and exercise capacity at rest and at peak exercise

\begin{tabular}{|c|c|c|c|c|c|c|c|c|c|}
\hline & \multirow[b]{3}{*}{$\mathrm{n}$} & \multicolumn{4}{|c|}{ NT-proBNP at rest } & \multirow{2}{*}{\multicolumn{2}{|c|}{$\frac{\text { NT-proBNP at peak exercise }}{\text { level }}$}} & \multirow{2}{*}{\multicolumn{2}{|c|}{$\begin{array}{l}\triangle N T \text {-proBNP } \\
\text { level }\end{array}$}} \\
\hline & & \multicolumn{2}{|l|}{ level } & \multicolumn{2}{|l|}{ ratio } & & & & \\
\hline & & $\bar{r}$ & $p$ & $r$ & $p$ & $\bar{r}$ & $p$ & $\bar{r}$ & $p$ \\
\hline \multicolumn{10}{|l|}{$6 \mathrm{MWT}$} \\
\hline Distance (m) & 61 & -0.507 & $<0.001$ & -0.328 & 0.010 & -0.490 & $<0.001$ & -0.256 & 0.047 \\
\hline$\%$ of norm & 61 & -0.546 & $<0.001$ & -0.481 & $<0.001$ & -0.534 & $<0.001$ & -0.310 & 0.015 \\
\hline Breaks (n) & 63 & 0.556 & $<0.001$ & 0.484 & $<0.001$ & 0.541 & $<0.001$ & 0.183 & 0.152 \\
\hline Borg scale & 63 & 0.271 & 0.032 & 0.245 & 0.053 & 0.260 & 0.039 & 0.033 & 0.800 \\
\hline \multicolumn{10}{|l|}{ Hemodynamics } \\
\hline Mean PAP (mmHg) & 63 & 0.341 & 0.006 & 0.521 & 0.001 & 0.335 & 0.007 & 0.110 & 0.391 \\
\hline Cardiac output (I/min) & 62 & -0.322 & 0.011 & -0.228 & 0.074 & -0.325 & 0.01 & -0.215 & 0.093 \\
\hline Cardiac index $\left(1 / \mathrm{min} / \mathrm{m}^{2}\right)$ & 36 & -0.384 & 0.021 & -0.360 & 0.031 & -0.384 & 0.021 & -0.248 & 0.145 \\
\hline PVR (wood units) & 56 & 0.359 & 0.007 & 0.476 & $<0.001$ & 0.361 & 0.006 & 0.226 & 0.094 \\
\hline Mean RAP (mmHg) & 57 & 0.231 & 0.083 & 0.281 & 0.034 & 0.220 & 0.100 & 0.149 & 0.269 \\
\hline $\mathrm{SVO}_{2}(\%)$ & 61 & -0.530 & $<0.001$ & -0.443 & $<0.001$ & -0.515 & $<0.001$ & -0.208 & 0.107 \\
\hline \multicolumn{10}{|l|}{ Lung function } \\
\hline DLCO (\%) & 44 & -0.332 & 0.028 & -0.270 & 0.077 & -0.314 & 0.038 & -0.182 & 0.238 \\
\hline $\mathrm{PaO}_{2}$ at rest $(\mathrm{mmHg})$ & 63 & -0.312 & 0.013 & -0.233 & 0.066 & -0.295 & 0.019 & -0.029 & 0.824 \\
\hline $\mathrm{PaO}_{2}$ at exercise $(\mathrm{mmHg})$ & 63 & -0.221 & 0.081 & -0.174 & 0.171 & -0.202 & 0.113 & -0.068 & 0.599 \\
\hline \multicolumn{10}{|l|}{ CPET } \\
\hline Work (watts) & 63 & -0.438 & $<0.001$ & -0.280 & 0.026 & -0.410 & 0.001 & -0.074 & 0.567 \\
\hline $\mathrm{VO}_{2}(\mathrm{ml} / \mathrm{min})$ & 63 & -0.492 & $<0.001$ & -0.335 & 0.007 & -0.473 & $<0.001$ & -0.136 & 0.289 \\
\hline $\mathrm{VO}_{2} / \mathrm{kg}$ & 63 & -0.514 & $<0.001$ & -0.436 & $<0.001$ & -0.490 & $<0.001$ & -0.193 & 0.130 \\
\hline AT $(\mathrm{ml} / \mathrm{min} / \mathrm{kg})$ & 48 & -0.307 & 0.034 & -0.335 & 0.062 & -0.272 & 0.020 & -0.165 & 0.263 \\
\hline $\mathrm{O}_{2}$ pulse $(\mathrm{ml} / \mathrm{min} /$ beat $)$ & 62 & -0.362 & 0.004 & -0.290 & 0.022 & -0.356 & 0.004 & -0.089 & 0.491 \\
\hline Ve $(1 / \mathrm{min})$ & 63 & -0.024 & 0.853 & 0.092 & 0.472 & -0.007 & 0.955 & 0.183 & 0.151 \\
\hline $\mathrm{Ve} / \mathrm{NO}_{2}$ & 49 & 0.479 & $<0.001$ & 0.398 & 0.005 & 0.463 & 0.001 & 0.241 & 0.096 \\
\hline $\mathrm{Ve} / \mathrm{NCO}_{2}$ & 49 & 0.465 & 0.001 & 0.361 & 0.011 & 0.446 & 0.001 & 0.219 & 0.131 \\
\hline $\mathrm{AaDO}_{2}(\mathrm{mmHg})$ & 63 & 0.452 & $<0.001$ & 0.395 & 0.001 & 0.442 & $<0.001$ & 0.320 & 0.011 \\
\hline $\mathrm{Vd} / \mathrm{Nt}(\%)$ & 62 & 0.349 & 0.005 & 0.296 & 0.019 & 0.335 & 0.008 & 0.130 & 0.314 \\
\hline $\mathrm{Ve} / \mathrm{NCO}_{2}$ slope & 62 & 0.471 & $<0.001$ & 0.435 & $<0.001$ & 0.466 & $<0.001$ & 0.330 & 0.009 \\
\hline
\end{tabular}


clinical worsening or short-term mortality in PAH [1]. While only a very mild $\triangle$ NT-proBNP could be demonstrated for the group with a low NT-proBNP at rest, the NT-proBNP response to exercise increased with rising baseline levels. For example, comparable exerciseinduced NT-proBNP changes could be demonstrated in patients from our low-level group and study participants in the trial by Völkers et al. [12]. We therefore conclude that, like in left heart disease $[9,10]$, NT-proBNP at rest seems to be a predictor for the exercise-induced $\triangle \mathrm{NT}$ proBNP.

PH patients with a strong NT-proBNP response to exercise are supposed to be limited primarily by RV dysfunction due to an impaired lung perfusion. Indeed, we found in PAH that both NT-proBNP at rest and NTproBNP at peak exercise are significantly correlated with hemodynamics. These findings are in accordance with an earlier study, where NT-proBNP at rest has been found to be an independent predictor for hemodynamic parameters in cardiopulmonary diseases [3]. We also found a strong correlation of NT-proBNP and NTproBNP at peak exercise with CPET parameters, as exercise capacity is believed to be primarily limited by cardiopulmonary function [13]. No such correlations were found between NT-proBNP and its response to exercise with parameters of lung function, as NTproBNP gives only indirect information about ventilation. Because the NT-proBNP response to exercise is baseline-dependent in PAH, neither NT-proBNP at peak exercise nor $\triangle \mathrm{NT}$-proBNP correlated better with prognostic parameters than NT-proBNP at rest.

Unarguably, our study has limitations. First, due to the advanced age of the study cohort, comorbidity might have biased the results. To reduce this effect, we excluded patients with severe kidney dysfunction, congenital heart disease or patients with acute right heart failure. Second, the NT-proBNP response to exercise might be different in PAH subgroups. Finally, the prognostic relevance of our observations remains unclear, as our study does not include long-term follow up results.

\section{Conclusions}

Despite these limitations, we conclude the following: NT-proBNP increases in response to exercise in PAH. The $\triangle$ NT-proBNP seems to be baseline-dependent. Both NT-proBNP at rest and NT-proBNP at peak exercise are significantly correlated with hemodynamics and functional capacity. Neither NT-proBNP at peak exercise nor $\triangle$ NT-proBNP correlated better with surrogate markers of disease severity than NTproBNP at rest. Thus, the NT-proBNP response to exercise does not contribute to a better assessment of disease severity in PAH.

\section{Additional file}

Additional file 1: Correlation plots of NT-proBNP at rest and at peak exercise and the $\triangle N T$-proBNP with the $6 \mathrm{MWT}$ distance, mean PAP and the $\mathrm{VO}_{2} / \mathrm{kg}$. (ZIP $\left.540 \mathrm{~kb}\right)$

\section{Abbreviations}

$6 \mathrm{MWT}$ : Six-minute walking testing; $\mathrm{AaDO}_{2}$ : Alveolar-arterial oxygen difference at peak exercise; AT: Anaerobic threshold; BMI: Body mass index; Cl: Cardiac index; CO: Cardiac output; CPET: Cardiopulmonary exercise testing; DLCO: Lung diffusing capacity for carbon monoxide; FEV1: Forced expiratory volume in one second; FVC: Forced vital capacity; NT-proBNP ratio: NT-proBNP level at rest divided by the age-adjusted normal upper range; NT-proBNP: N-terminal pro-brain-type natriuretic peptide; PAH: Pulmonary arterial hypertension; $\mathrm{PaO}_{2}$ : Arterial oxygen pressure; PAP: Pulmonary arterial pressure; PCWP: Pulmonary capillary wedge pressure; PH: Pulmonary hypertension; PVR: Pulmonary vascular resistance; RAP: Right atrial pressure; RV: Right ventricular; SEM: Standard error of mean; $\mathrm{SVO}_{2}$ : Mixed venous oxygen saturation; TLC: Total lung capacity; Vd/ Vt: Functional dead space ventilation at peak exercise; Ve: Peak minute ventilation; $\mathrm{Ve} / \mathrm{NCO}_{2}$ slope: Slope of minute ventilation to carbon dioxide output; $\mathrm{Ve/}$ $\mathrm{VCO}_{2}$ : Carbon dioxide equivalent at anaerobic threshold; $\mathrm{VeNO}_{2}$ : Oxygen equivalent at anaerobic threshold; $\mathrm{VO}_{2}$ : Peak oxygen uptake; $\Delta \mathrm{NT}$ proBNP: NT-proBNP level at exercise minus NT-proBNP level at rest

\section{Acknowledgements}

All authors acknowledge the excellent assistance of Yvonne Eglinger in proof reading the manuscript.

\section{Funding}

The study was conducted without funding.

\section{Availability of data and materials}

The datasets used and analysed during the current study are available from the corresponding author on reasonable request.

\section{Authors' contributions}

WS, MS and TMB conceived and designed the study. CF and MS acquired the study data. JK performed the statistical analysis. JK and TMB drafted the article. All authors participated in interpreting the data and revised the manuscript for important intellectual content. All authors approved the final version of the manuscript.

\section{Ethics approval and consent to participate}

The study was conducted in accordance with current ethical standards and was approved by the ethics committee at the Klinikum Augsburg (reference number 201604).

\section{Consent for publication}

Not applicable.

\section{Competing interests}

The authors declare that they have no competing interests.

\section{Publisher's Note}

Springer Nature remains neutral with regard to jurisdictional claims in published maps and institutional affiliations.

Received: 31 May 2017 Accepted: 28 December 2017

Published online: 15 January 2018

\section{References}

1. Galiè N, Humbert M, Vachiery UL, Gibbs S, Lang I, Torbicki A, Simonneau G, Peacock A, Vonk Noordegraaf A, Beghetti M, Ghofrani A, Gomez Sanchez MA, Hansmann G, Klepetko W, Lancellotti P, Matucci M, McDonagh T, Pierard LA, Trindade PT, Zompatori M, Hoeper M, Aboyans V, Vaz Carneiro A, Achenbach S, Agewall S, Allanore Y, Asteggiano R, Paolo Badano L, Albert Barberà J, Bouvaist H, Bueno H, Byrne RA, Carerj S, Castro G, Erol Ç, Falk V, Funck-Brentano C, Gorenflo M, Granton J, lung B, Kiely DG, Kirchhof P, Kjellstrom B, Landmesser U, Lekakis J, Lionis C, Lip GY, Orfanos SE, Park MH, 
Piepoli MF, Ponikowski P, Revel MP, Rigau D, Rosenkranz S, Völler H, Luis Zamorano J. 2015 ESC/ERS guidelines for the diagnosis and treatment of pulmonary hypertension: the joint task force for the diagnosis and treatment of pulmonary hypertension of the European Society of Cardiology (ESC) and the European Respiratory Society (ERS): endorsed by: Association for European Pediatric and Congenital Cardiology (AEPC), International Society for Heart and Lung Transplantation (ISHLT). Eur Heart J. 2016;37(1):67-119.

2. Nickel N, Golpon H, Greer M, Knudsen L, Olsson K, Westerkamp V, Welte T, Hoeper MM. The prognostic impact of followup assessments in patients with idiopathic pulmonary arterial hypertension. Eur Respir J. 2012;39(3): 589-96. https://doi.org/10.1183/09031936.00092311.

3. Lewis GD, Bossone E, Naeije R, Grünig E, Saggar R, Lancellotti P, Ghio S, Varga J, Rajagopalan S, Oudiz R, Rubenfire M. Pulmonary vascular hemodynamic response to exercise in cardiopulmonary diseases. Circulation. 2013;128(13): 1470-9. https://doi.org/10.1161/CIRCULATIONAHA.112.000667.

4. Hall C. Essential biochemistry and physiology of (NT-pro)BNP. Eur J Heart Fail. 2004;6(3):257-60.

5. Souza R, Jardim C, Julio Cesar Fernandes C, Silveira Lapa M, Rabelo R, Humbert M. NT-proBNP as a tool to stratify disease severity in pulmonary arterial hypertension. Respir Med. 2007;101(1):69-75.

6. Wasserman K, Handen J, Sue D. Principles of exercise testing and interpretation. Philadelphia, USA: Lippincott Williams \& Wilkins; 2004.

7. Borg G. Borg's perceived exertion and pan scales. Champaign, IL: Human Kinetics; 1998.

8. Capoulade R, Magne J, Dulgheru R, Hachicha Z, Dumesnil JG, O'Connor K, Arsenault M, Bergeron S, Pierard LA, Lancellotti P, Pibarot P. Prognostic value of plasma B-type natriuretic peptide levels after exercise in patients with severe asymptomatic aortic stenosis. Heart. 2014;100(20):1606-12.

9. Kato M, Kinugawa T, Ogino K, Endo A, Osaki S, Igawa O, Hisatome I, Shigemasa C. Augmented response in plasma brain natriuretic peptide to dynamic exercise in patients with leftventricular dysfunction and congestive heart failure. J Intern Med. 2000;248(4):309-15.

10. Maeder MT, Staub D, Surnier Y, Reichlin T, Noveanu M, Breidthardt T, Potocki M, Schaub N, Conen D, Mueller C. Determinants of absolute and relative exercise-induced changes in B-type natriuretic peptides. Int J Cardiol. 2011;147(3):409-15. https://doi.org/10.1016/j.jijcard.2009.09.546.

11. Grachtrup S, Brügel M, Pankau H, Halank M, Wirtz H, Seyfarth HJ. Exercise dependence of $\mathrm{N}$-terminal pro-brain natriuretic peptide in patients with precapillary pulmonary hypertension. Respiration. 2012;84(6):454-60. https:// doi.org/10.1159/000334950.

12. Völkers M, Rohde D, Zelniker T, Weiss CS, Giannitsis E, Katus HA, Meyer FJ, High-sensitive Troponin T increase after exercise in patients with pulmonary arterial hypertension. BMC Pulm Med. 2013;13:28. https://doi.org/10.1186/ 1471-2466-13-28.

13. Arena R, Myers J, Williams MA, Gulati M, Kligfield P, Balady GJ, Collins E, Fletcher G. Assessment of functional capacity in clinical and research settings: a scientific statement from the American Heart Association Committee on exercise, rehabilitation, and prevention of the council on clinical cardiology and the council on cardiovascular nursing. Circulation. 2007:116:329-43

\section{Submit your next manuscript to BioMed Central and we will help you at every step:}

- We accept pre-submission inquiries

- Our selector tool helps you to find the most relevant journal

- We provide round the clock customer support

- Convenient online submission

- Thorough peer review

- Inclusion in PubMed and all major indexing services

- Maximum visibility for your research

Submit your manuscript at www.biomedcentral.com/submit

) Biomed Central 